\title{
PERAN ORGANIZATIONAL IDENTIFICATION SEBAGAI MEDIATOR PENGARUH JOB INSECURITY TERHADAP ISLAMIC ORGANIZATIONAL CITIZENSHIP BEHAVIOR DAN KINERJA KARYAWAN
}

\author{
Andi Nur Azizah Hafsah ${ }^{1}$ \\ Program Studi Manajemen, Fakultas Bisnis dan Ekonomika Universitas Islam Indonesia, \\ Yogyakarta, Indonesia, azizahhafsah11@gmail.com \\ Muafi MUAFI2, * \\ Program Studi Manajemen, Fakultas Bisnis dan Ekonomika Universitas Islam Indonesia, \\ Yogyakarta, Indonesia, muafi@uii.ac.id \\ *Corresponding author
}

\begin{abstract}
Background - PT. Long Bagun Prima Sawit is a company that runs in the oil palm plantation industry often gets a public spotlight. News with a viewpoint that is not profitable for PT. Long Bagun Prima Palm This is certainly indirectly can affect the behavior and performance of its employees. Likewise, the opposite, news or the company's positive image will also make proud employees with a high level of organizational identification
\end{abstract}

Aim - This study tested and analyzed the influence of job insecurity against Islamic OCB and employee performance mediated by organizational identification.

Design / Methodology / Approach - The research approach used in this study was a quantitative approach by distributing questionnaires to respondents. The population studied in this study were employees of PT. LNG Bagun Prima Sawit totaling 78 people. The data analysis method used in this study is Structural Equation Model (SEM) using the Partial Least Square (pls).

Results and Discussion - The results of this study indicate that the job insecurity has a negative effect on organizational identification. This shows that the higher the level of job insecurity felt by employees, the level of self-identification of employees of the company will decline so even the opposite. While organizational identification has a positive effect on Islamic OCB and employee performance. When employees identify themselves with the company, the Islamic OCB behavior and employee performance will be maximal. In addition, organizational identification also proved to mediate job insecurity with Islamic OCB and employee performance. High self-identification of the company will weaken the negative influence of job insecurity and increase the Islamic OCB behavior and employee performance.

Conclusion - Organizational Identification is proven to have a positive effect on Islamic OCB. Organizational identification is proven to have a positive effect on employee performance, but job insecurity is proven to have a negative effect on organizational identification. While organizational identification is proven to mediate the influence of job insecurity against Islamic OCB and employee performance.

Research Implication - The implications of this study provide an overview of companies to further emphasize organizational identification because it is proven to provide good influence both Islamic OCB and employee performance. In order to grow organizational identification in the company, the employee job insecurity must be minimized.

Keywords: Job, Insecurity, Organizational, Islamic, Employee, Performance

\begin{abstract}
Abstrak
Latar Belakang - PT. Long Bagun Prima Sawit merupakan perusahaan yang berjalan dalam industri perkebunan kelapa sawit kerap mendapatkan sorotan publik. Berita dengan sudut pandang yang kurang menguntungkan pihak PT. Long Bagun Prima Sawit ini tentunya secara tidak langsung dapat mempengaruhi prilaku serta kinerja karyawannya. Begitu juga sebaliknya, berita atau citra positif perusahaan juga akan membuat bangga karyawan dengan tingkat identifikasi organisasi yang tinggi
\end{abstract}


Tujuan - Penelitian ini menguji dan menganalisis pengaruh job insecurity terhadap Islamic OCB dan kinerja karyawan dimediasi Oleh organizational identification.

Desain/ Metodologi/ Pendekatan - Pendekatan penelitian yang digunakan dalam penelitian ini adalah pendekatan kuantitatif dengan menyebarkan kuesioner kepada responden. Populasi yang diteliti dalam penelitian ini adalah karyawan PT. Lng Bagun Prima Sawit yang berjumlah 78 orang. Metode analisis data yang digunakan dalam penelitian ini adalah Structural Equation Model (SEM) dengan menggunakan Partial Least Square (PLS).

Hasil dan Pembahasan - Hasil dari penelitian ini menunjukkan bahwa job insecurity berpengaruh negatif terhadap organizational identification. Hal ini menunjukkan bahwa semakin tinggi tingkat job insecurity yang dirasakan oleh karyawan maka tingkat identifikasi diri karyawan terhadap perusahaan akan menurun begitu pun sebaliknya. Sedangkan organizational identification berpengaruh positif terhadap Islamic $O C B$ dan kinerja karyawan. ketika karyawan mengidentifikasikan dirinya dengan perusahaan, maka perilaku Islamic $O C B$ dan kinerja karyawanpun akan maksimal. Selain itu, organizational identification juga terbukti memediasi hubungan job insecurity dengan Islamic OCB dan kinerja karyawan. Identifikasi diri yang tinggi terhadap perusahaan akan memperlemah pengaruh negatif job insecurity dan meningkatkan perilaku Islamic OCB dan kinerja karyawan.

Kesimpulan - Organizational Identification terbukti berpengaruh positif terhadap Islamic OCB. Organizational identification terbukti berpengaruh positif terhadap kinerja karyawan, namun Job insecurity terbukti berpengaruh negatif terhadap organizational identification. Sedangkan Organizational identification terbukti memediasi pengaruh job insecurity terhadap Islamic OCB dan kinerja karyawan.

Implikasi Penelitian - Penelitian ini memberikan gambaran bagi perusahaaan untuk lebih menekankan organizational identification karena terbukti memberikan engaruh baik baik islamic OCB dan kinerja karyawan. Guna menumbuhkan organizational identification di perusahaan, maka job insecurity karyawan harus diminimalkan.

Kata Kunci: Job, Insecurity, Organisasional, Islami, Kinerja, Karyawan

\section{PENDAHULUAN}

Era globalisasi saat ini membuat perusahaan-perusahaan harus mampu menghadapi tantangan dan juga menangkap berbagai peluang yang ada. Perusahaan dituntut tidak hanya mampu bertahan tapi juga unggul di bidangnya. Sumberdaya manusia sendiri yang merupakan penggerak utama dari sebuah organisasi atau perusahaan harus memiliki kekuatan agar mampu menjadi keunggulan dari perusahaan.Sebagai salah satu penggerak penting dalam perusahaan, tenaga kerja atau sumber daya manusia tentu harus dijaga dan juga dipenuhi kebutuhannya. Pemenuhan kebutuhan tersebut dilakukan dari hirarki atau urutan tingkatan paling bawah ke atas. Di tingkatan dasar ada kebutuhan fisiologis (phisiological needs), kebutuhan keamanan (safety needs), kebutuhan social (social needs), kebutuhan pemenuhan harga diri (esteem needs), dan yang terakhir kebutuhan aktualisasi diri (selfactualization) (Armstrong., 2009).

Pemenuhan kebutuhan keamanan, perusahaan harus memperhatikan aspekaspek yang dapat mempengaruhi ketidakamanan pekerjaan yang dapat dirasakan oleh karyawan. Menurut Greenhalgh. (1984) ketidakamanan pekerjaan atau job insecurity adalah perasaan tidak berdaya yang dirasakan oleh karyawan untuk mempertahankan 
keberlanjutan pekerjaan yang disebabkan oleh ancaman situasi dari suatu pekerjaan. Hubungan timbal balik atau pertukaran menurut teori social exchange menjelaskan bahwa terdapat anteseden di dalam lingkungan kerja, yaitu hubungan interpersonal atau hubungan pertukaran sosial. Di mana sesorang akan memberikan manfaatnya jika ia juga menerima manfaat lain (Cohen., 2007). Pemenuhan keamanan terhadap pekerjaan merupakan salah satu faktor penting dalam mengidentifikasikan diri karyawan terhadap perusahaan. Identifikasi organisasi adalah konsep yang mengacu pada sejauh atau sedalam apa karyawan mendefinisikan diri mereka sendiri sebagai anggota atau bagian dari organisasi serta sedalam apa mereka merasakan kesatuan dengan organisasi tempatnya bekerja (Ashforth dan Mael., 1989).

Kinerja karyawan yang baik akan membantu perusahaan dalam mencapai tujuannya. Kinerja sendiri didefinisikan sebagai aksi nyata yang dilakukan oleh karyawan sesuai dengan perannya didalam perusahaan (Bohlander., 2013). Tetapi, tujuan perusahaan ataupun pencapaian perusahaan akan cepat tercapai ketika karyawan tidak hanya menyelesaikan pekerjaan yang sesuai dengan job description, melainkan ikut membantu menyelesaikan tugas yang berada di luar tanggung jawabnya. Contohnya seperti membantu rekan kerja menyelesaikan pekerjaannya, di mana perilaku ini disebut dengan extra role atau organizational citizenship behavior (OCB). Menurut perspektif Islamic OCB perilaku OCB dapat didasarkan pada nilai-nilai keislaman terdapat empat indikator pengukuran yaitu Ta'awun, Civic Virtue, Da'wah, dan Ra'fal Haraj (Kamil., 2014).

Sebagai perusahaan yang berjalan dalam industri perkebunan kelapa sawit PT. Long Bagun Prima Sawit kerap mendapatkan sorotan publik. Berita dengan sudut pandang yang kurang menguntungkan pihak PT. Long Bagun Prima Sawit ini tentunya secara tidak langsung dapat mempengaruhi prilaku serta kinerja karyawannya. Begitu juga sebaliknya, berita atau citra positif perusahaan juga akan membuat bangga karyawan dengan tingkat identifikasi organisasi yang tinggi (Ting dan Ho, 2017). Hal tersebut dapat berpengaruh pada kinerja karyawan baik secara kinerja sesuai dengan deskripsi pekerjaan maupun kinerja extra role atau OCB karyawan (Dahiya, 2021; Picolli., et al., 2017).

\section{TINJAUAN PUSTAKA}

\section{Job insecurity dan Organizational Identification}

Menurut Greenhalgh (1984) perasaan tidak berdaya yang dirasakan oleh karyawan untuk mempertahankan keberlanjutan pekerjaannya yang disebabkan oleh 
ancaman situasi dari suatu pekerjaan dapat disebut job insecurity. Ancaman yang dirasakan oleh karyawan tidak hanya ancaman kehilangan pekerjaan, namun juga ancaman akan kehilangan kesempatan mengembangkan kemampuan, kesempatan di jenjang karir, serta ketidak jelasan tanggung jawab. job insecurity dianggap sebagai salah satu sumber stres paling berbahaya dalam kehidupan masyarakat kontemporer (de Witte et al., 2016).

Pertukaran menurut teori social exchange menjelaskan bahwa sesorang akan memberikan manfaatnya jika ia juga menerima manfaat lain (Cohen., 2007). Job insecurity merupakan suatu hal negatif yang diberikan oleh perusahaan kepada karyawan. Hal ini tentu saja dapat mempengaruhi beberapa aspek, salah satunya organizational identification. Identifikasi organisasi adalah karyawan melibatkan rasa keterkaitan yang kuat dengan kelompok, dan kayawan yang sangat teridentifikasi menganggap diri dan organisasi mereka sebagai kesatuan (Giessner., 2011). Jika mengacu pada teori pertukaran sosial maka semakin tinggi tingkat ketidakamanan kerja maka identifikasi organisasional akan semakin kecil. Chirumbolo et al.(2017) menemukan bahwa qualitative job insecurity berhubungan negatif dengan identifikasi organisasi. Didukung oleh Asif et al.(2019) menemukan bahwa Hasil penelitian menunjukkan bahwa ketidakamanan kerja kualitatif mempengaruhi identifikasi organisasi serta kinerja pekerjaan secara negatif, sedangkan identifikasi organisasi menunjukkan dampak positif terhadap kinerja pekerjaan. Berdasarkan hubungan dua variabel tersebut maka diajukan hipotesis sebagai berikut:

$\mathrm{H} 1$ : Terdapat pengaruh negatif dari job insecurity terhadap organizational identification

Organizational Identification dan Islamic OCB

Organ (1988) dalam Podsakoff et al., 2000) mendefinisikan OCB sebagai perilaku karyawan yang deskresioner sehingga tidak diakui secara langsung oleh sistem penghargaan formal. Perilaku tersebut lebih merupakan masalah pilihan pribadi, sehingga kelalaian dalam melakukannya tidak dapat dijadikan sebagai acuan hukuman. Menurut Kamil. (2014) OCB dalam perspektif Islam tidak hanya mengarah pada hasil positif organisasi atau individu yang lebih tinggi di dunia ini, seperti yang dianut dalam literatur OCB Barat, tetapi juga memperkuat ikatan seorang muslim dengan Allah, karena pekerjaan itu sendiri dipandang sebagai tindakan ibadah. Terdapat beberapa penelitian yang dilakukan untuk mendalami Islamic OCB. Kamil et al. (2014) meneliti tentang dimensi pengukuran $\mathrm{OCB}$ dalam perspektif Islam dan ditemukan bahwa 
terdapat empat indikator pengukuran yaitu Ta'awun, Civic Virtue, Da'wah, dan Ra'fal Haraj.

Terdapat beberapa penelitian yang menemukan bahwa terdapat pengaruh positif organizational identification pada Islamic OCB. Tufan dan Wendt. (2020) juga menemukan bahwa identifikasi organisasi memediasi hubungan pelanggaran konrtak psikologis terkait relasional dan keragaman terhadap OCB. Sementara pelanggaran kontrak psikologis transaksional secara langsung mempengaruhi OCB. Berdasarkan hubungan kedua variabel tersebut maka diajukan hipotesis sebagai berikut:

H2: Terdapat pengaruh positif dari organizational identification terhadap Islamic $O C B$

\section{Organizational Identification dan Kinerja Karyawan}

Kinerja sendiri didefinisikan sebagai aksi nyata yang dilakukan oleh karyawan sesuai dengan perannya didalam perusahaan (Snell dan Bohlander, 2013). Sedangkan Rotundo.(2002), kinerja diartikan sebagai perilaku dan tindakan secara sukarela yang dilakukan oleh karyawan untuk mencapai tujuan perusahaan. Kinerja yang dimaksud haruslah terukur dan jelas. Sehingga dapat ditentukan tingkat keberhasilan organisasi serta tindakan apa yang harus dilakukan. Diamantidis \& Chatzoglou. (2019) terdapat beberapa faktor yang mempengaruhi kinerja karyawan, antara lain: lingkungan pekerjaan, dukungan manajemen, kemampuan adaptasi, dan motivasi.

Hubungan organizational identification terhadap kinerja karyawan juga didasarkan pada teori identitas sosial, di mana karyawan yang menidenfikasikan dirinya dengan perusahaan akan cenderung menampilkan kinerja yang baik. Hal ini dikarenakan karyawan dengan identifikasi organisaasi yang tinggi merasa tujuan perusahaan merupakan tujuan pribadi. Hal ini didukung oleh penelitian Sulaiman dan Abdullah. (2019) yang menemukan bahwa karyawan dengan identifikasi yang kuat cenderung memiliki emosi yang lebih besar, keterlibatan kognitif dan fisik dan tampil lebih baik dalam pekerjaan mereka. Selanjutnya, Ting dan Ho. (2017) juga melakukan penelitian yang menunjukkan hubungan antara identifikasi organisasi dengan kinerja. Penelitian ini menemukan bahwa Organizational identification berpengaruh positif terhadap kinerja. Motivasi pelayanan publik menghasilkan tingkat identifikasi organisasi yang lebih tinggi dan mengarah ke tingkat kinerja yang lebih tinggi karena pegawai negeri sipil menganggap nasib dan hasil organisasi sebagai milik mereka. Berdasarkan hubungan kedua variabel tersebut maka hipotesis yang diajukan sebagai berikut:

H3: Terdapat pengaruh positif dari organizational identification terhadap kinerja karyawan. 
Job Insecurity, Organizational Identification, Islamic OCB, dan Kinerja Karyawan

Hubungan timbal balik atau pertukaran menurut teori social exchange menjelaskan bahwa seseorang akan memberikan manfaatnya jika ia juga menerima manfaat lain (Cohen., 2007). Sehingga karyawan yang mendapatkan perasaan tidak adil dan/atau job insecurity juga akan memberikan kesan negatif kepada perusahaan. Sedangkan hubungan organizational identification dengan Islamic $O C B$ kinerja karyawan dijelaskan dengan teori identitas sosial. Pada penelitian yang dilakukan oleh Dahiya (2021) menunjukkan hubungan antara ketidakamanan pekerjaan dan perilaku kewarganegaraan organisasi sepenuhnya dimediasi oleh identifikasi organisasi. Namun, identifikasi organisasi sebagian dimediasi hubungan antara ketidakamanan pekerjaan dan kinerja tugas.

Penelitian Picolli et al. (2017) ketidakamanan kerja terkait dengan penurunan tingkat identifikasi dengan organisasi, akibatnya kinerja tugas dan kinerja kontekstual yang rendah. Temuan ini menunjukkan bahwa perilaku karyawan dalam konteks pekerjaan yang tidak aman juga didorong oleh evaluasi tentang perasaan memiliki organisasi. Berdasarkan adanya hubungan antara job insecurity, organizational identification, Islamic $O C B$ dan kinerja karyawan maka hipotesis yang diajukan sebagai berikut:

H4: organizational identification memediasi hubungan antara job insecurity dan Islamic $O C B$

H5: organizational identification memediasi hubungan antara job insecurity terhadap kinerja karyawan.

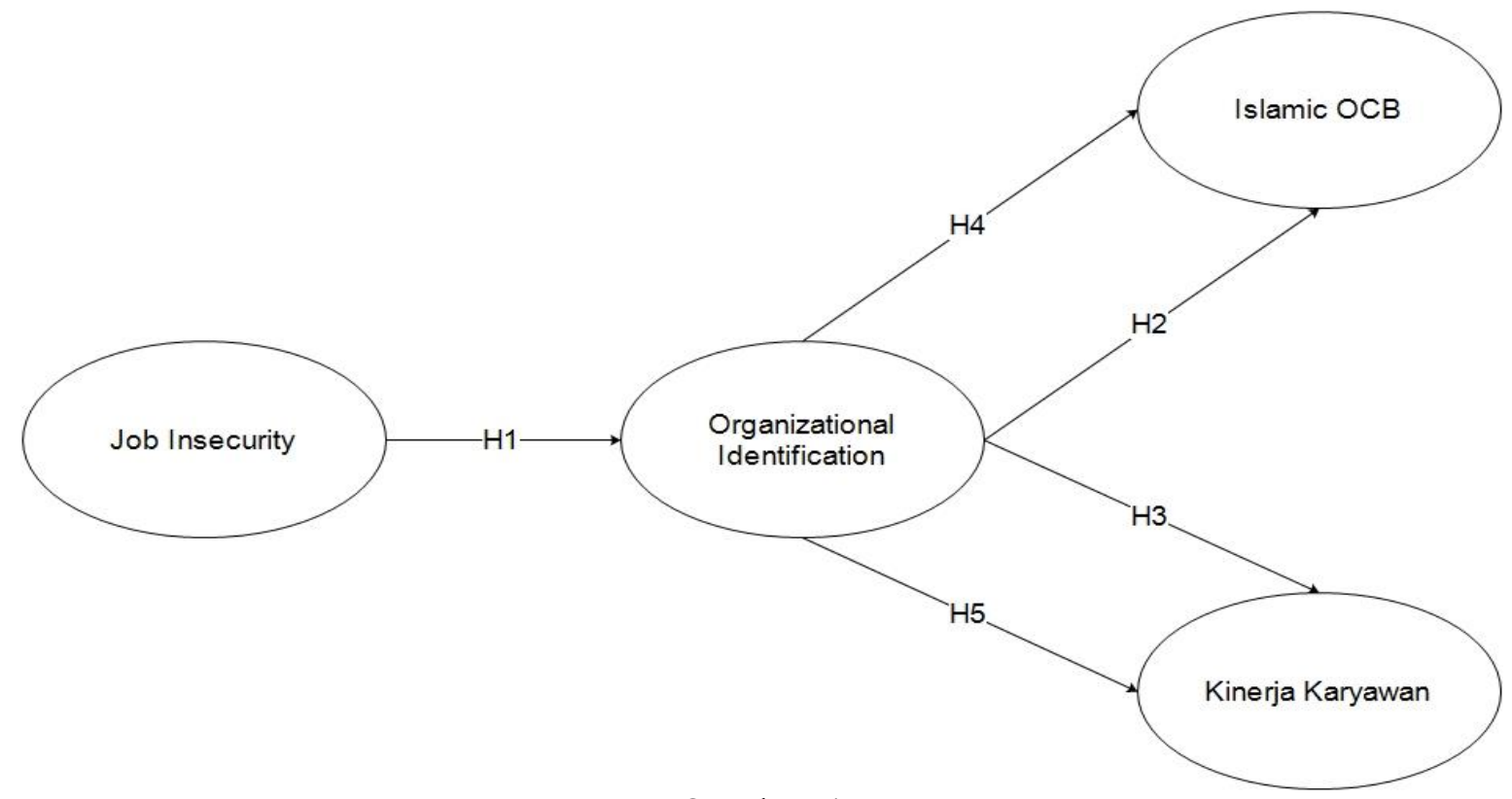

Gambar 1

Kerangka Penelitian 


\section{METODOLOGI PENELITIAN}

Penelitian ini menggunakan pendekatan kuantitatif dengan survei melalui teknik kuesioner. Penelitian ini dilakukan di PT. Long Bagun Prima Sawit yang berlokasi di kecamatan Karangan kabupaten Kutai Timur Provinsi Kalimantan Timur. Populasi dalam penelitian ini adalah seluruh karyawan PT. Long Bagun Prima Sawit yang berjumlah 89 orang. Pengambilan sampel dilakukan dengan menggunakan teknik sensus. Sampel sensus adalah teknik yang digunakan dalam pengambilan sampel dengan menggunakan seluruh populasi sebagai sampel. Sampel dalam penelitian ini adalah seluruh karyawan PT. Long Bagun Prima Sawit yang berjumlah 89 orang. Tetapi, kuesioner yang kembali dan layak di olah berjumlah 78 kuesioner.

Pengukuran Islamic $O C B$ dalam penelitian ini mengacu pada Kamil. (2014) dengan indikator Ta'awun, Civic Virtue, Da'wah, dan Ra'fal Haraj. Analisis yang dilakukan adalah Evaluasi Model Pengukuran (Outer Model) dan Evaluasi Model Struktural (inner model).

\section{HASIL DAN PEMBAHASAN}

\section{Deskripsi Responden}

Penelitian ini memiliki responden laki-laki lebih banyak dari responden perempuan. Responden laki-laki berjumlah 66 responden atau terhitung $85 \%$, sedangkan responden perempuan berjumlah 12 responden atau terhitung 15\%. Menurut usia, responden terbanyak dengan usia antara 20 sampai 30 tahun yang berjumlah 52 responden atau terhitung 67\%, sedangkan responden dengan jumlah paling kecil terletak pada rentang usia antara 30 tahun sampai 40 tahun yang hanya berjumlah lima responden atau sebesar $6 \%$. Berdasarkan masa kerja, responden dengan jumlah terbanyak adalah yang menjalani masa kerja satu tahun dengan jumlah 32 responden dan terhitung 41\%, sedangkan responden dengan masa kerja dibawah satu tahun adalah jumlah responden paling sedikit yaitu 10 responden atau $13 \%$. Sedangkan berdasarkan pendidikan akhir, responden pada penelitian ini tidak ada yang memiliki riwayat pendidikan akhir SD, S2 dan S3. Responden terbanyak adalah yang memiliki pendidikan akhir SLTA yaitu 69 responden dan terhitung 88\%.

\section{Deskripsi Variabel}

Pada Penelitian ini dihasilkan rekapitulasi deskripsi variabel yang tertuang pada tabel 1. Dari hasil yang ditampilkan dilihat bahwa responden menilai variabel job insecurity dengan nilai rata-rata 2,980 dengan kategori sedang. Sedangkan variabel Islamic $O C B$ dengan nilai 4,026 dengan kategori tinggi. Variabel kinerja karyawan dengan nilai 3,975 kriteria tinggi. Serta menilai variabel organizational identification dengan rata-rata nilai 3,784 kriteria tinggi. 
Tabel 1

Deskripsi Variabel

\begin{tabular}{clrc} 
No. & Variabel & Rata-Rata & Kriteria \\
1. & Job Insecurity & 2.98 & Sedang \\
2. & Organizational Identification & 3.784 & Tinggi \\
3. Islamic OCB & 4.026 & Tinggi \\
4. & Kinerja Karyawan & 3.975 & Tinggi \\
\hline \multicolumn{2}{r}{ Sumber: Hasil Olah Data, 2021 }
\end{tabular}

\section{Hasil Penelitian}

\section{Outer Model}

1. Validitas konvergensi

Tabel 2 menunjukkan bahwa seluruh indikator memiliki nilai loading factor di atas 0,70 maka dapat dikatakan bahwa seluruh indikator dalam penelitian ini valid dan dapat digunakan penelitian.

2. Validitas Konstruk

Sesuai yang ada pada tabel di atas seluruh variabel memiliki nilai AVE lebih dari 0,50 sehingga keseluruhan memiliki nilai validitas konstruk yang baik. pada validitas konstruk symbol S menandakan signifikan yang artinya secara konstruk hubungan antar variabel dari kerangka penelitian yang diajukan dapat dijabarkan positif oleh perhitungan statistik
3. Validitas diskriminan

Tabel 4 menunjukkan nilai AVE setiap variabel lebih tinggi daripada nilai korelasi variabel tersebut terhadap variabel lainnya. Sehingga dapat dikatakan bahwa setiap variabel memiliki validitas diskriminan yang baik.

4. Realibilitas komposit

Tabel 5 menujukkan seluruh variabel dalam penelitian memiliki nilai composite reability di atas 0,70 dan cornbach's alpha di atas 0,60 sehingga dapat dikatakan seluruh variabel yang diuji valid dan realiabel serta dapat dilanjutkan untuk pengujian model struktural.

Tabel 2

Uji Validitas Konvergensi

\begin{tabular}{|c|c|c|c|}
\hline Variabel & Item & loading factor & Deskripsi \\
\hline \multirow{5}{*}{ job insecurity } & $\mathrm{JI} 1$ & 0.808 & valid \\
\hline & JI2 & 0.773 & valid \\
\hline & JI3 & 0.844 & valid \\
\hline & JI4 & 0.801 & valid \\
\hline & JI5 & 0.779 & valid \\
\hline
\end{tabular}




\begin{tabular}{|c|c|c|c|}
\hline Variabel & Item & loading factor & Deskripsi \\
\hline & JI6 & 0.812 & valid \\
\hline & JI7 & 0.771 & valid \\
\hline \multirow{6}{*}{$\begin{array}{l}\text { Organizational } \\
\text { identification }\end{array}$} & OI1 & 0.886 & valid \\
\hline & OI2 & 0.717 & valid \\
\hline & OI3 & 0.830 & valid \\
\hline & OI4 & 0.805 & valid \\
\hline & OI5 & 0.791 & valid \\
\hline & OI6 & 0.875 & valid \\
\hline \multirow{19}{*}{ Islamic OCB } & OCB1 & 0.822 & valid \\
\hline & OCB1 1 & 0.848 & valid \\
\hline & OCB12 & 0.797 & valid \\
\hline & OCB13 & 0.774 & valid \\
\hline & OCB14 & 0.789 & valid \\
\hline & OCB15 & 0.710 & valid \\
\hline & OCB16 & 0.727 & valid \\
\hline & OCB 17 & 0.746 & valid \\
\hline & OCB18 & 0.778 & valid \\
\hline & OCB19 & 0.742 & valid \\
\hline & OCB2 & 0.716 & valid \\
\hline & OCB20 & 0.803 & valid \\
\hline & OCB2 1 & 0.758 & valid \\
\hline & OCB3 & 0.821 & valid \\
\hline & OCB4 & 0.785 & valid \\
\hline & OCB5 & 0.721 & valid \\
\hline & OCB6 & 0.738 & valid \\
\hline & OCB8 & 0.792 & valid \\
\hline & OCB9 & 0.814 & valid \\
\hline \multirow{13}{*}{$\begin{array}{l}\text { Kinerja } \\
\text { karyawan }\end{array}$} & $\mathrm{P} 1$ & 0.835 & valid \\
\hline & $\mathrm{P} 10$ & 0.754 & valid \\
\hline & $\mathrm{P} 11$ & 0.831 & valid \\
\hline & $\mathrm{P} 12$ & 0.853 & valid \\
\hline & $\mathrm{P} 13$ & 0.804 & valid \\
\hline & P15 & 0.783 & valid \\
\hline & P16 & 0.711 & valid \\
\hline & $\mathrm{P} 17$ & 0.806 & valid \\
\hline & P18 & 0.723 & valid \\
\hline & $\mathrm{P} 2$ & 0.846 & valid \\
\hline & P3 & 0.791 & valid \\
\hline & P4 & 0.743 & valid \\
\hline & P5 & 0.798 & valid \\
\hline
\end{tabular}




$\begin{array}{cccc}\text { Variabel } & \text { Item } & \text { loading factor } & \text { Deskripsi } \\ & \text { P6 } & 0.734 & \text { valid } \\ \text { P7 } & 0.711 & \text { valid } \\ \text { P8 } & 0.840 & \text { valid } \\ \text { P9 } & 0.873 & \text { valid }\end{array}$

Sumber: Data Primer Diolah 2021

Tabel 3

Uji Validitas Konstruk

\begin{tabular}{|l|c|c|c|c|}
\hline & $\begin{array}{c}\text { Cronbach's } \\
\text { Alpha }\end{array}$ & rho_A & $\begin{array}{c}\text { Composite } \\
\text { Reliability }\end{array}$ & (AVE) \\
\hline Islamic OCB & 0.963 & 0.964 & 0.966 & 0.599 \\
\hline Job Insecurity & 0.907 & 0.925 & 0.925 & 0.638 \\
\hline Kinerja Karyawan & 0.963 & 0.967 & 0.966 & 0.627 \\
\hline Organizational Identification & 0.901 & 0.909 & 0.924 & 0.671 \\
\hline
\end{tabular}

Sumber: Data Primer Diolah 2021

Sumber: Data Primer Diolah, 2021

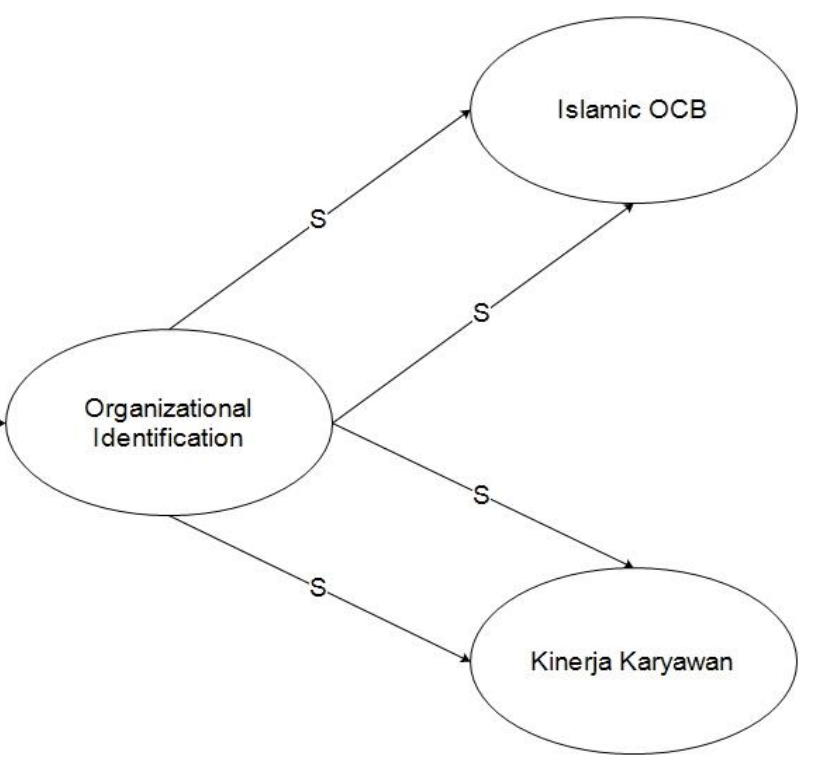

Gambar 2

Hubungan antar variabel pada validitas konstruk

Tabel 4

Uji Validitas Diskriminan

\begin{tabular}{ccccc}
\multicolumn{5}{l}{ Fornell-Larcker Criterion } \\
& IOCB & JI & KK & OI \\
IOCB & 0.774 & & & \\
JI & -0.604 & 0.799 & & \\
KK & 0.721 & -0.415 & 0.792 & \\
OI & 0.781 & -0.557 & 0.718 & 0.819 \\
\hline
\end{tabular}

Sumber: Data Primer Diolah, 2021 
Tabel 5

Uji Reliabilitas Komposit

\begin{tabular}{lrr} 
& $\begin{array}{c}\text { Cronbach's } \\
\text { Alpha }\end{array}$ & $\begin{array}{c}\text { Composite } \\
\text { Reliability }\end{array}$ \\
\hline Islamic OCB & 0.963 & 0.966 \\
Job Insecurity & 0.907 & 0.925 \\
Kinerja Karyawan & 0.963 & 0.966 \\
Organizational & 0.901 & 0.924 \\
Identification & & \\
Sumber: Data Primer Diolah, 2021 & &
\end{tabular}

\section{Uji Hipotesis}

Pengujian hipotesis dapat dinilai dari ouput inner model melalui proses bootstrapping pada software SmartPLS yang dilihat pada bagian tabel path coefficient (tabel 6). Selanjutnya dievaluasi menggunakan nilai dari $t$-statistic. Jika nilai t-statistik lebih dari 1,96 dan p-value kurang dari 0,05 dengan tingkat signifikansi $5 \%$ maka item pengukuran dianggap penting dan dapat dilihat pengaruh positif atau negatif antar variabel.

1. Job insecurity berpengaruh negatif dan signifikan terhadap organizational identification. Pengaruh tersebut dapat dilihat dari nilai $\mathrm{P}$-values $0.000<0.05$ dan t-statistic $7.319>1.96$. Sehingga berdasarkan perhitungan tersebut hipotesis $\mathrm{H} 1$ menyatakan bahwa job insecurity berpengaruh negatif dan signifikan terhadap organizational identification diterima

2. Organizational identification berpengaruh positif dan signifikan pada Islamic OCB. Hal tersebut dapat dilihat dari nilai $p$-values $0.000<0.05$ dan nilai t-statistic $\quad 10.259>1.96 . \quad$ Maka berdasarkan perhitungan tersebut hipotesis H2 yang menyatakan bahwa organizational identification berpengaruh positif dan signifikan terhadap Islamic OCB diterima.

3. Organizational identification berpengaruh positif dan signifikan terhadap kinerja karyawan. Hal ini ditunjukkan pada nilai p-values $0.000<0.005$ dan nilai $t$-statistic 6.456>1.96. Sehingga berdasarkan perhitungan nilai tersebut, hipotesis $\mathrm{H} 3$ organizational identification berpengaruh positif dan signifikan terhadap kinerja karyawan diterima.

Pengujian hipotesis mediasi juga dapat dinilai dari ouput inner model melalui proses bootstrapping pada software Smart PLS yang dilihat pada bagian tabel specific indirect effect. Selanjutnya dievaluasi menggunakan nilai dari $t$-statistic. Jika nilai t-statistik lebih dari 1,96 dan p-value kurang dari 0,05 dengan tingkat signifikansi 5\% maka item pengukuran dianggap 
penting dan dapat dilihat pengaruh positif atau negatif antar variabel.

1. Organizational identification secara signifikan dapat memediasi hubungan antara job insecurity dengan Islamic $O C B$. Pengaruh signifikan tersebut dibuktikan dengan nilai p-values $0.000<0.05$ dan nilai $t$-statistic 4.766>1.96. Berdasarkan perhitungan tersebut maka hipotesis $\mathrm{H} 4$ yang menyatakan bahwa organizational identification memediasi hubungan antara job insecurity dan Islamic $O C B$ diterima.
2. Organizational identification secara signifikan dapat memediasi hubungan antara job insecurity dengan kinerja karyawan. Berdasarkan nilai yang ditunjukkan pada Tabel 4.14 p-value menunjukkan angka $0.000<0.05$ dan $t$ statistic menunjukkan angka 4.248>1.96, maka hipotesis H5 yang menyatakan bahwa organizational identification memediasi hubungan antara job insecurity terhadap kinerja karyawan diterima.

Tabel 6

Uji hipotesis

\begin{tabular}{|c|c|c|c|c|c|c|}
\hline & $\begin{array}{l}\text { Original } \\
\text { Sample } \\
\text { (O) }\end{array}$ & $\begin{array}{l}\text { Sample } \\
\text { Mean } \\
\text { (M) }\end{array}$ & $\begin{array}{l}\text { Standard } \\
\text { Devition } \\
\text { STDEV) }\end{array}$ & $\begin{array}{c}\mathrm{T} \\
\text { Statistics }\end{array}$ & $\begin{array}{c}\text { P } \\
\text { Values }\end{array}$ & Keterangan \\
\hline $\begin{array}{l}\text { Job Insecurity } \rightarrow \text { Organizational } \\
\text { Identification }\end{array}$ & $-0,557$ & $-0,560$ & 0,076 & 7,319 & $0,000^{*}$ & H1 Diterima \\
\hline $\begin{array}{l}\text { Organizational Identification } \rightarrow \\
\text { Islamic OCB }\end{array}$ & 0.781 & 0,779 & 0,076 & 10,259 & $0,000^{*}$ & H2 Diterima \\
\hline $\begin{array}{l}\text { Organizational Identification } \rightarrow \\
\text { Kinerja Karyawan }\end{array}$ & 0.718 & 0,717 & 0,111 & 6,56 & $0,000^{*}$ & H3 Diterima \\
\hline $\begin{array}{l}\text { Job Insecurity } \rightarrow \text { Organizational } \\
\text { Identification } \rightarrow \text { Islamic OCB }\end{array}$ & $-0,435$ & $-0,0$ & 0,091 & 4,766 & $0,000^{*}$ & Signifikan \\
\hline $\begin{array}{l}\text { Job Insecurity } \rightarrow \text { Organizational } \\
\text { Identification } \rightarrow \text { Kinerja Karyawan }\end{array}$ & $-0,400$ & $-0,06$ & 0,09 & 4,248 & $0,000 *$ & Signifikan \\
\hline
\end{tabular}

\section{Pembahasan}

\section{Pengaruh Job Insecurity Terhadap Organizational Identification}

Hipotesis pertama dalam penelitian ini adalah job insecurity berpengaruh negatif dan signifkan terhadap organizational identification. Hal ini mendukung penelitian yang dilakukan oleh Chirumbolo et al.(2017) bahwa qualitative job insecurity berhubungan negatif dengan identifikasi organisasi. Dalam hal ini, semakin tinggi tingkat ketidakamanan pekerjaan yang dirasakan oleh karyawan maka semakin rendah identifikasi diri karyawan terhadap 
perusahaan. Keamanan kerja merupakan suatu elemen penting dalam identifikasi diri karyawan terhadap perusahaan. Hal ini mendukung penelitiannya Asif et al.(2019)seorang karyawan menerima banyak manfaat dari suatu organisasi, tingkat identifikasi organisasinya tinggi. Sebaliknya, jika manfaat yang diperoleh dari organisasi rendah, tingkat identifikasi organisasinya rendah. Hal ini membuat job insecurity dianggap sebagai salah satu sumber stres paling berbahaya dalam kehidupan masyarakat kontemporer (deWitte et al., 2016). Ali et al.(2020) menegaskan bahwa kehilangan karakteristik pekerjaan yang signifikan akan berdampak pada perasaan negatif karyawan, yang mengurangi identifikasi karyawan terhadap perusahaan. Dengan demikian, semakin rendah tingkat job insecurity yang dirasakan oleh karyawan, maka identifikasi diri karyawan terhadap perusahaan semakin meningkat.

Karyawan PT. Long Bagun Prima Sawit tidak merasakan job insecurity yang terlalu tinggi, dapat dilihat dari analisis deskriptif yang memiliki nilai rata-rata total dengan kategori sedang. Dijelaskan pada item memiliki nilai rata-rata tertinggi yaitu "Saya merasa tidak nyaman jika kehilangan pekerjaan saya dalam waktu dekat". Artinya, karyawan PT. Long bagun Prima Sawit merasakan ketidakamanan pekerjaan. Karyawan yang merasakan job insecurity adalah karyawan yang tidak siap jika mengalami pemutusan hubungan kerja dalam waktu dekat. Hal ini juga dapat didukung oleh masa kerja karyawan yang mayoritas singkat sehingga dapat mempengaruhi tingkat job insecurity karyawan PT. Long Bagun Prima Sawit. Karena tingkat job insecurity yang dirasakan oleh karyawan PT. Long Bagun Prima Sawit masih tergolong kategori sedang, sehingga penilaian terhadap organizational identification pun masih terbilang tinggi. Item yang terpengaruh cukup besar adalah "Ketika seseorang memuji organisasi ini, itu terasa seperti pujian pribadi". Artinya, ketika organisasi mendapatkan pujian dari pihak lain, maka karyawan tidak menganggapnya sebagai pujian untuk dirinya sendiri. Meski sudah masuk kedalam kategori penilaian tinggi, perusahaan dapat meningkatkan rasa identifikasi diri karyawan melalui pemberian otonomi pada karyawan serta menumbuhkan rasa saling memiliki dalam praktik kerja, sehingga ketika perusahaan mendapatkan pujian, maka karyawan pun akan merasakannya seperti pujian pribadi.

\section{Pengaruh Organizational Identification Terhadap Islamic OCB}

Hasil penelitian ini sesuai dengan hasil penelitian Tufan dan Wendt (2020) yang menegaskan bahwa Identifikasi organisasi adalah prediktor kunci dari hasil sikap dan perilaku terkait pekerjaan yang penting 
termasuk OCB, karyawan yang sangat teridentifikasi adalah mereka yang melakukan perilaku peran tambahan, bukan karena mereka diharuskan tetapi karena konsep diri mereka berakar pada keberhasilan organisasi.

Hal tersebut mendukung hasil penelitian ini di mana identifikasi organisasi karyawan PT. Long Bagun Prima Sawit memiliki nilai rata-rata dengan kategori tinggi. Tercermin pada item yang memiliki nilai rata-rata tertinggi yaitu "Keberhasilan organisasi ini adalah kesuksesan saya". Item ini mendapat perhatian lebih oleh karyawan. Artinya, karyawan PT. Long Bagun Prima Sawit sudah menunjukkan identifikasi organisasi yang baik. Selaras dengan hasil tersebut, tingkat Islamic $O C B$ juga mendapatkan penilaian dengan ratarata total tinggi pada setiap itemnya. Terdapat beberapa item yang mendapatkan perhatian sangat tinggi oleh karyawan yaitu, "Saya melakukan pekerjaan saya dengan cara terbaik untuk mendapatkan ridho Allah SWT" dan "Saya dengan tulus membantu rekan kerja saya untuk mendapatkan ridho Allah SWT". Artinya, kesadaran karyawan dalam berperilaku ekstra yang didasarkan pada nilai-nilai keislaman menunjukkan level yang baik. Karyawan dengan identifikasi organisai yang tinggi memiliki kesadaran bahwa perilaku ekstra dan tolong menolong sesama karyawan lain dilakukan untuk mendapatkan Ridha Allah SWT tanpa mengharapkan imbalan lain. Dalam hal ini, perusahaan dapat terus mempertahankan serta meningkatkan identifikasi diri karyawan terhadap perusahaan dan dampak positifnya terhadap Islamic $O C B$ yang meningkat.

\section{Pengaruh Organizational Identification Terhadap Kinerja Karyawan}

Hasil dari analisis hipotesis ketiga yaitu Organizational Identification berpengaruh positif dan signifikan terhadap kinerja karyawan PT. Long Bagun Prima Sawit. Penelitian ini menegaskan bahwa identifikasi karyawan terhadap PT. Long Bagun Prima Sawit, meningkatkan kinerja karyawan. Hal ini sesuai juga dengan penelitian Ting dan Ho.(2017) yang menunjukkan hubungan antara identifikasi organisasi dengan kinerja. Penelitian ini menemukan bahwa Organizational identification berpengaruh positif terhadap kinerja karyawan. Ketika karyawan mengidentifikasi secara kuat dengan suatu organisasi, mereka lebih termotivasi untuk bekerja lebih rajin dan memastikan keberhasilan organisasi. Karyawan dengan semangat kerja mencurahkan banyak waktu untuk tugas dan kegiatan yang berhubungan dengan pekerjaan. Sulaiman dan Abdullah. (2019) juga menemukan bahwa karyawan dengan identifikasi yang kuat cenderung memiliki emosi yang lebih 
besar, keterlibatan kognitif dan fisik dan tampil lebih baik dalam pekerjaan mereka.

Karyawan PT. Long Bagun Prima Sawit memiliki tingkat identifikasi diri terhadap perusahaan yang tinggi. Karyawan beranggapan bahwa kesuksesan perusahaan merupakan keberhasilan individu karyawan. Asumsi tersebut menghasilkan tingkat kinerja karyawanjuga semakin tinggi. Dengan asumsi, jika karyawan memberikan kinerja yang tinggi maka keberhasilan perusahaan juga akan terjadi. Kinerja karyawan yang baik ditunjukkan pada item yang mendapatkan perhatian paling banyak dari karyawan yaitu "saya biasa untuk menyelesaikan tugas saya tepat waktu". Karyawan yang menyelesaikan tugasnya tepat waktu merupakan indikator pada penilaian kinerja karyawan. Identifikasi diri karyawan terhadap PT. Long Bagun Prima Sawit membuat karyawan mampu bekerja dengan baik tanpa memerlukan banyak pengawasan sesuai dengan butir "Saya mampu menangani tugas saya tanpa banyak pengawasan". Hal tersebut memberi persepsi bahwa dengan adanya identifikasi organisasional menumbuhkan kesadaran untuk berkinerja dengan baik tanpa perlu adanya paksaan dan tekanan dari perusahaan. Untuk itu perusahaan harus mampu menjaga tingkat identifikasi diri karyawan terhadap perusahaan agar terus dapat mendapatkan hasil kinerja maksimal dari karyawan.

\section{Organizational Identification Memediasi}

\section{Pengaruh Job Insecurity Terhadap}

\section{Islamic OCB dan Kinerja Karyawan}

Penelitian ini juga mengkaji hubungan antara job insecurity pada Islamic OCB dan kinerja karyawan dengan organizational identification sebagai mediator. Hasil penelitian menunjukkan bahwa organizational identification mampu memediasi hubungan antara job insecurity terhadap Islamic $O C B$ dan kinerja karyawan. Ini berarti bahwa organizational identification memperlemah hubungan job insecurity dengan Islamic $O C B$ dan kinerja karyawan. Identifikasi diri yang tinggi terhadap perusahaan bisa memperlemah pengaruh negatif job insecurity dan meningkatkan perilaku Islamic OCB. Begitu pun dengan kinerja karyawan, identifikasi organisasional yang tinggi mampu meningkatkan kinerja karyawan dan mengurangi pengaruh negatif job insecurity. Hasil penelitian ini mendukung hasil penelitian Rotundo (2002) yang menghasilkan bahwa organizational identification terbukti memediasi pengaruh job insecurity terhadap OCB. Hasil tersebut membuktikan bahwa job insecurity tidak secara langsung mempengaruhi hasil perilaku, tetapi efeknya melalui organizational identification. Karyawan menghargai keanggotaan organisasi mereka 
karena memberikan dasar yang kuat untuk rasa memiliki dan keamanan, memberikan sumber validasi diri tentang kesesuaian sikap dan perilaku mereka (Piccoli et al., 2017). Penelitian ini menegaskan bahwa dengan mengabaikan rasa keamanan karyawan terhadap pekerjaannya dapat mempengaruhi tingkat identifikasi diri karyawan terhadap perusahaan. Karyawan PT.Long Bagun Prima Sawit masih merasakan ketidakamanan dalam pekerjaannya. Karyawan memiliki ketakutan terbesar terhadap kehilangan pekerjaan dalam kurun waktu dekat. Artinya penelitian ini menggambarkan bahwa pengendalian dan pengurangan rasa tidak aman pada pekerjaan dapat meningkatkan identifikasi organisasi, selain itu identifikasi organisasi yang tinggi mampu meningkatkan Islamic OCB dan kinerja karyawan. Karena alih-alih mencari cara untuk meningkatkan identifikasi organizational, pengendalian job insecurity karyawan juga harus mendapatkan perhatian sehingga Islamic OCB dan kinerja karyawan juga dapat meningkat.

\section{KESIMPULAN}

Berdasarkan penelitian di atas maka dapat disimpulkan sebagai berikut:

1. Job insecurity terbukti berpengaruh negatif terhadap organizational identification karyawan PT. Long Bagun Prima Sawit. Hal ini menunjukkan bahwa semakin tinggi tingkat job insecurity yang dirasakan oleh karyawan maka tingkat identifikasi diri karyawan terhadap perusahaan semakin menurun begitu pun sebaliknya.

2. Organizational Identification terbukti berpengaruh positif terhadap Islamic $O C B$ pada karyawan PT. Long Bagun Prima Sawit. Hasil penelitian ini menunjukkan bahwa ketika karyawan mengidentifikasikan dirinya dengan perusahaan, maka perilaku Islamic $O C B$ pun makin maksimal.

3. Organizational identification terbukti berpengaruh positif terhadap kinerja karyawan. Dengan didasarkan pada teori identifikasi sosial, dalam hal ini karyawan mengidentifikasikan dirinya dengan perusahaannya menganggap bahwa tujuan perusahaan adalah tujuan individu itu sendiri sehingga karyawan tersebut dapat berkontribusi maksimal dalam pencapaian tujuan perusahaan melalui kinerja.

4. Organizational identification terbukti memediasi pengaruh job insecurity terhadap Islamic OCB. Hasil penelitian ini menunjukkan Identifikasi diri yang tinggi terhadap perusahaan terbukti mampu memperlemah pengaruh negatif job insecurity dan meningkatkan perilaku Islamic $O C B$ 
5. Organizational identification terbukti memediasi pengaruh job insecurity terhadap kinerja karyawan identifikasi organisasional yang tinggi mampu meningkatkan kinerja karyawan dan mengurangi pengaruh negatif job insecurity. Berarti efek negatif dari job insecurity yang dirasakan karyawan tidak selalu menurunkan kinerja karyawan karena efek tersebut dapat dikurangi dengan adanya tingkat identifikasi diri karyawan terhadap organisasi yang tinggi.

\section{IMPLIKASI PENELITIAN}

Penelitian ini memberikan gambaran bagi perusahaaan untuk lebih menekankan organizational identification karena terbukti memberikan engaruh baik baik oslamic OCB dan kinerja karyawan. Guna menumbuhkan organizational identification di perusahaan, maka job insecurity karyawan harus diminimalkan.

\section{DAFTAR PUSTAKA}

Ali, I., Ali, M., Grigore, G., Molesworth, M., \& Jin, Z. (2020). The moderating role of corporate reputation and employee-company identification on the work-related outcomes of job insecurity resulting from workforce localization policies. Journal of Business Research, 117(February), 825-838. https://doi.org/10.1016/j.jbusres.2019.02.060

Armstrong, M. (2009). Armstrong's Handbook of Performance Management (4th ed.). London and Philadelphia.

Ashforth, B. E., \& Mael, F. (1989). Social Identity Theory and the Organization. The Academy of Management Review, 14(1), 20-39. http://www.jstor.org/stable/258189

Asif, R., Fiaz, M., Khaliq, Z., \& Nisar, S. (2019). Estimating The Mediating Role Of Organizational Identification In Determining The Relationship Between Qualitative Job Insecurity And Job Performance. Journal of Managerial Sciences, 13.

Chirumbolo, A., Urbini, F., Callea, A., \& Talamo, A. (2017). The impact of qualitative job insecurity on identification with the organization: The moderating role of overall organizational justice. Swiss Journal of Psychology, 76(3), 117-123. https://doi.org/10.1024/1421-0185/a000197

Cohen, A. (2007). Identities at Work. Identities at Work, January. https://doi.org/10.1007/9781-4020-4989-7

Dahiya, R. (2021). Insecure people can eclipse your sun; so identify before it is too late: revisit to the nexus between job insecurity, organizational identification and employee performance behaviour. Evidence-Based HRM.

https://doi.org/https://doi.org/10.1108/EBHRM-05-2020-0063

deWitte, H., Pienaar, J., \& de Cuyper, N. (2016). Review of 30 Years of Longitudinal Studies on the Association Between Job Insecurity and Health and Well-Being: Is There Causal 
Evidence? Australian Psychologist, 51(1), 18-31. https://doi.org/10.1111/ap.12176

Diamantidis, A. D., \& Chatzoglou, P. (2019). Factors affecting employee performance: an empirical approach. International Journal of Productivity and Performance Management, 68(1), 171-193. https://doi.org/10.1108/IJPPM-01-2018-0012

Giessner, S. R. (2011). Is the merger necessary? the interactive effect of perceived necessity and sense of continuity on post-merger identification. Human Relations, 64(8), 1079-1098. https://doi.org/10.1177/0018726711406979

Greenhalgh, L. (1984). Managing the job insecurity crisis. Human Resource Management, 22(4), 431-444. https://doi.org/10.1002/hrm.3930220409

Kamil, N. M., Sulaiman, M., Osman-Gani, A. M., \& Ahmad, K. (2014). Investigating the dimensionality of organisational citizenship behaviour from Islamic perspective (OCBIP): Empirical analysis of business organisations in southeast Asia. Asian Academy of Management Journal, 19(1), 17-46.

Piccoli B., Antonio Callea and Flavio U., \& Antonio Chirumbolo., Emanuela Ingusci ., H. D. W. (2017). Job insecurity and performance: the mediating role of organizational identification. Personal Review, 46(8), 1508-1522. https://doi.org/10.1108/JEA-06-2013-0067

Podsakoff, P. M., MacKenzie, S. B., Paine, J. B., \& Bachrach, D. G. (2000). Citizenship Behaviors: A Critical Review of the Theoretical and Empirical Literature and Suggestions for Future Research. Journal of Management, 26(3), 513-563. https://doi.org/10.1016/s0149-2063(00)00047-7

Rotundo, M. (2002). The relative importance of task, citizenship, and counterproductive performance to global ratings of job performance: a policy-capturing approach. The Journal of Applied Psychology, 87(1), 66-80. https://doi.org/10.1037/0021-9010.87.1.66

Snell, S., \& Bohlander, G. (2013). Managing Human Resources (16th ed.). South-Western, Cengage Learning.

Sulaiman, N. S., \& Abdullah, Z. (2019). Conceptual Exploration on Internal Communication and Organizational Identification As Determinants of Employee Performance. International Journal of Modern Trends in Social Sciences, 2(9), 99-115. https://doi.org/10.35631/ijmtss. 29009

Ting, S.-C., \& Ho, M.-H. (2017). The Influence of Workplace Friendship, Job Involvement, and Organizational Identification on Job Performance: Administrative Staffs of Private Science and Technology Universities in South Taiwan as an Example. International Journal of Humanities \& Social Sciences, 9(6), 46-58. http://ijhss.net/index.php/ijhss/

Tufan, P., \& Wendt, H. (2020). Organizational identification as a mediator for the effects of psychological contract breaches on organizational citizenship behavior: Insights from the perspective of ethnic minority employees. European Management Journal, 38(1), 179-190. https://doi.org/10.1016/j.emj.2019.07.001 